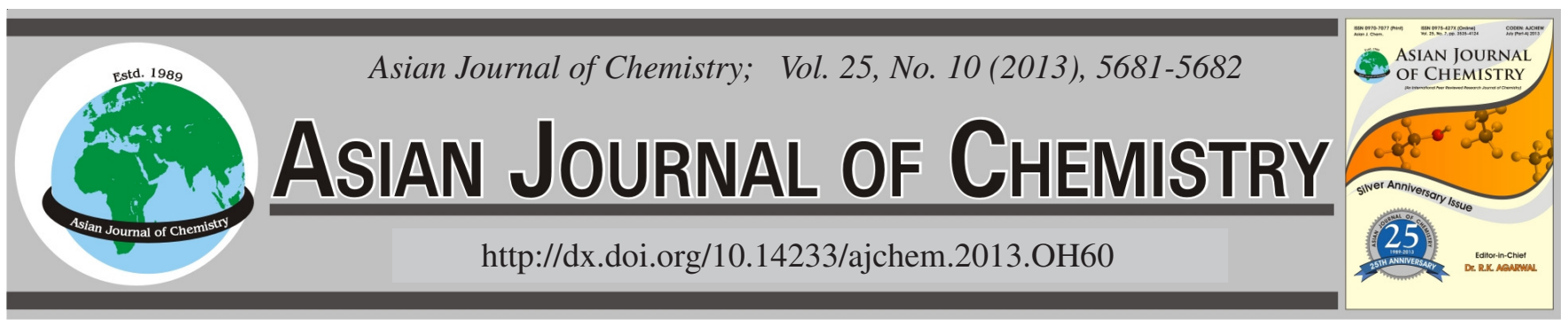

\title{
Study of Fly Ash Glass-Ceramic Surface Modification $\nmid$
}

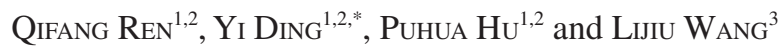

${ }^{1}$ Anhui Key Laboratory of Advanced Building Materials, Hefei 230601, P.R. China

${ }^{2}$ School of Materials and Chemical Engineering, Anhui University of Architecture, Hefei 230601, P.R. China

${ }^{3}$ Building Materials Research Institute, Dalian University of Technology, Hefei 230601, P.R. China

*Corresponding author: E-mail: dyrqf@aiai.edu.cn

AJC-13304

By ion exchanged to surface of fly ash glass-ceramic in the solution of $\mathrm{KNO}_{3}$ holding for $4 \mathrm{~h}$ at $300{ }^{\circ} \mathrm{C}$, flexure strength is enhanced $17 \%$. The ion exchange was thoroughly examined by energy spectrum analysis and lots of columnar crystal were found on the surface of glassceramic.

Key Words: Glass-ceramics, Ion exchanged, Flexure strength.

\section{INTRODUCTION}

Glass-ceramics, intended for building applications, constitute a well-developed and widespread way to absorb glasses obtained from treatment of several solid wastes (like fly ash $)^{1}$. The microcrystalline glass material properties depended on the glass phase volume, nature and the crystal grain size, crystal size, in the microcrystalline glass, physical and chemical properties and the structural relationship between glass phase and crystal ${ }^{2,3}$. Microcrystalline glass surface modification can be strengthened by coating and ion exchange. In recent years, research has primarily focused on ion exchange source liquid potassium salt bath ${ }^{4}$.

In this paper, the potassium ions of $\mathrm{KNO}_{3}$ solution exchange the surface sodium ion of our preparation fly ash microcrystalline glass was studied and testing the modified microcrystalline glass mechanical properties and microstructure.

\section{EXPERIMENTAL}

All chemicals used in present study were purchased and used as received without further purification and fly ash glassceramic was obtained by previous report ${ }^{5}$. In a typical procedure, two kinds of molten salt solution ion exchange, i.e., a certain amount of pure $\mathrm{KNO}_{3}$ in high temperature furnace under certain temperature for thermal insulation (the former is $300{ }^{\circ} \mathrm{C}$, the latter $600{ }^{\circ} \mathrm{C}$ ), ion exchange for $4 \mathrm{~h}$ in the clay crucible.

The field-emission scanning electron microscope (FESEM) measurements were carried out with a field-emission microscope (JEOL, 7500B) operated at an acceleration voltage of $10 \mathrm{kV}$.

\section{RESULTS AND DISCUSSION}

Table-1 shows after modified, density and flexural strength were both higher than before, water absorption is same. At the same time, the flexural strength of modification A modification effect can be modified better than modified B and in the volume density is in turn modified effect, but the difference is not large, almost no difference from the rate of change.

\begin{tabular}{cccc|cc}
\hline \multicolumn{1}{c}{ TABLE-1 } \\
& Before & \multicolumn{2}{c}{ Modified A } & \multicolumn{2}{c}{ Modified B } \\
\cline { 3 - 6 } & Modified & $\begin{array}{c}\text { Measured } \\
\text { value }\end{array}$ & $\begin{array}{c}\text { Change } \\
\text { rate }\end{array}$ & $\begin{array}{c}\text { Measured } \\
\text { value }\end{array}$ & $\begin{array}{c}\text { Change } \\
\text { rate }\end{array}$ \\
\hline Density & 2.7545 & 2.7606 & 1.002 & 2.7658 & 1.004 \\
$\begin{array}{c}\text { Flexural strength } \\
(\mathrm{MPa})\end{array}$ & 68.42 & 80.14 & 1.171 & 76.30 & 1.115 \\
$\begin{array}{c}\text { Water absorption } \\
\text { rate }(\%)\end{array}$ & 0 & 0 & 0 & 0 & 0 \\
\hline
\end{tabular}

The energy spectra of the modified sample can be observed as shown in Figs. 1 and 2. Figs. 1 and 2 show modified A and modified B containing $\mathrm{Na}$ components, that the two sample surface $\mathrm{K}$ ion has been replaced by $\mathrm{Na}$ ion after modification.

Crystal morphology changes through modification were shown in Figs. 3-5. 


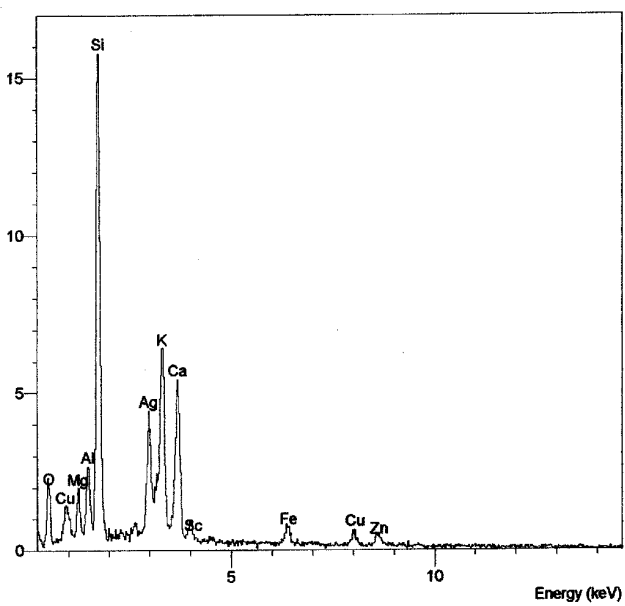

Fig. 1. Modified A

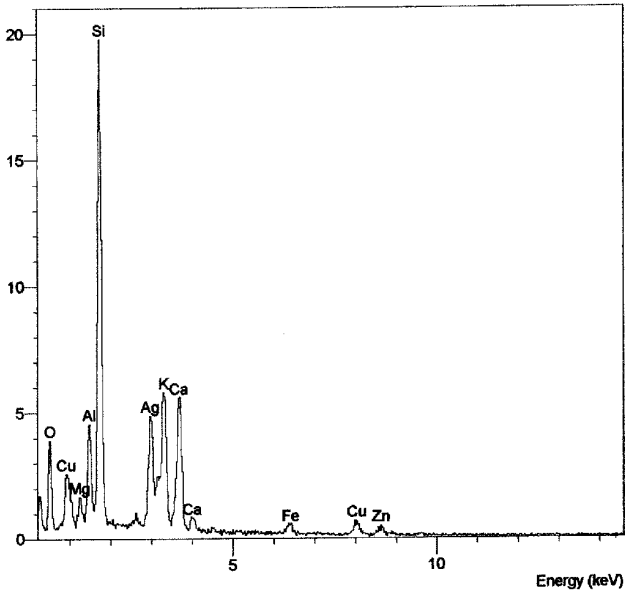

Fig. 2. Modified B

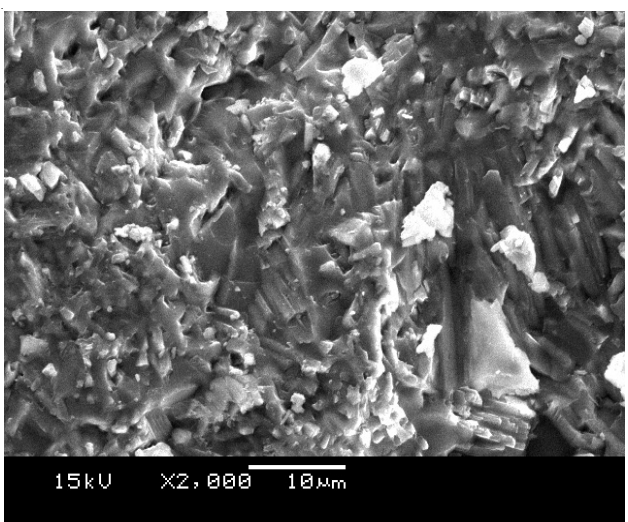

Fig. 3. SEM of un-modified sample

Fig. 3 shows the crystalline phases of microcrystalline glass scattered distribution in the glass phase and particles are small. Figs. 4 and 5 are in different molten potassium salt system for ion exchange. The SEM morphology showed the structure produced marked change, modified in A columnar crystals, with size of $5 \mu \mathrm{m} \times 1 \mu \mathrm{m}$ around and meshed together some of the surrounding elements, while the modified B crystal significantly smaller than modified A, but larger than the unmodified. Crystal become smaller, its mechanical perfor-mance is lower. Table- 1 showed that the modified 1 flexural strength is

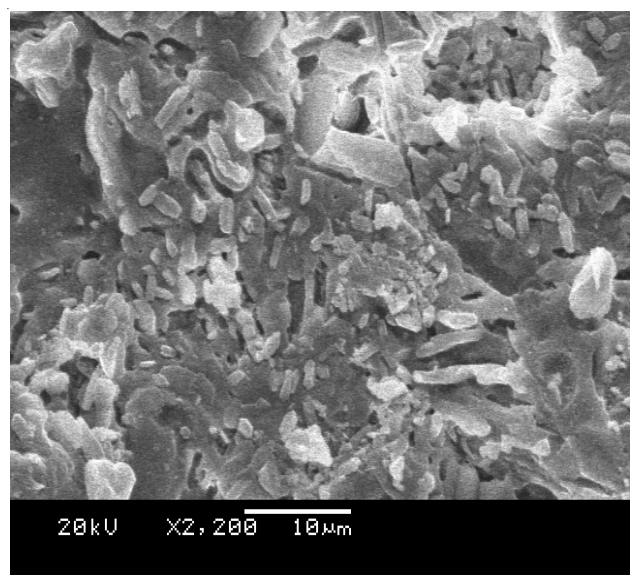

Fig. 4. Modified A

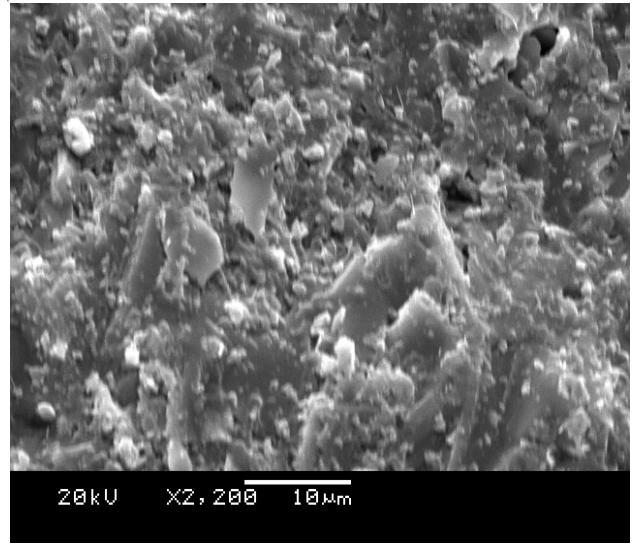

Fig. 5. Modified B

higher than the 2 modified and unmodified, suggesting reached certain enhancement effect.

\section{Conclusion}

In summery, the ion exchange results showed physical and chemical properties of modified fly ash glass-ceramics are higher than the unmodified. Through the microcrystal glass surface by ion exchange, at $300{ }^{\circ} \mathrm{C} \mathrm{KNO}_{3}$ solution heat for 4 $\mathrm{h}$, microcrystalline glass surface producing large columnar crystal by energy spectrum analysis and SEM analysis, intensity than unmodified increased by $17 \%$.

\section{ACKNOWLEDGEMENTS}

One of the authors (D.Y.) thank the financial support from Anhui University of Architecture College Students Open Fund (Grant C12096) and National College Students' Innovation Fundation (Grant 201210878068).

\section{REFERENCES}

1. Z. Strnad, Glass-Ceramic Materials, Elsevier Science Publishers, Amsterdam (1986).

2. F. Li and X.D. Liu, China Ceramics, 47, 19 (2011).

3. Q. Li, Y.Z. Mei, Z.W. Luo and A.X. Lu, Chinese J. Nonferrous Metals, 21, 1450 (2011).

4. C.Y. Wang and Y. Tao, Glass Surface and Surface Treatment. Beijing: China Building Materials Industry Press, pp. 47-49 (1993).

5. Q.F. Ren, Y. Ding, S.F. Zhu and P.H. Hu, Asian J. Chem., 24, 3973 (2012). 